integrated specialist teams can deliver high quality care to these vulnerable patients.

We would like to thank Mental Health Foundation and Research Into Ageing, who funded studies from which some of the data were acquired.

Contributors: All authors helped to formulate the study design, coordinate the collection of data, and write the paper.

$\mathrm{CB}$ undertook the data evaluation and will act as guarantor.

Funding: None.

Competing interests: None declared.

1 Kitwood T, Bredin K. Evaluating dementia care: the DCM method. 7th ed. Bradford: Bradford Dementia Research Group, 1997.
2 Brooker D. Looking at them looking at me. A review of observational studies into the quality of institutional care for elderly people with dementia. J Ment Health 1995;4:145-56.

3 Copeland JR, Kelleher MJ, Kellett JM, Gourlay AJ, Gurland BJ, Fleiss JL et al. A semi structured clinical interview for the assessment of diagnosis and mental state in the elderly. The geriatric mental state schedule: development. Psychol Med 1976;6:439-49.

4 Leaper R, ed. Training and qualifications for work with older people. Report of a national conference with recommendations for action. National Council on Ageing. London: Age Concern, 1998

5 Department of Health. Fit for the Future? National required standards for residential and nursing homes for older people. London: DoH, 1999 www.doh.gov.uk/pub/docs/doh/fitfuture.pdf (accessed 9 May 2001).

(Accepted 6 April 2001)

\title{
Prescriptions with potential drug interactions dispensed at Swedish pharmacies in January 1999: cross sectional study
}

Juan Merlo, Hans Liedholm, Ulf Lindblad, Agneta Björck-Linné, Jürgen Fält, Gunnar Lindberg, Arne Melander

The growing use of pharmacological agents means that drug interactions are of increasing interest for public health. ${ }^{1}$ Monitoring of potential drug interactions may improve the quality of drug prescribing and dispensing, and it might form a basis for education focused on appropriate prescribing.

\section{Participants, methods, and results}

In a cross sectional study, we analysed all prescriptions $(n=962013)$ involving two or more drugs dispensed to the Swedish population ( $\mathrm{n}=7214509$; age range 15-95) from all Swedish pharmacies $(\mathrm{n}=885)$ in January 1999. The data were taken from the Swedish healthcare database on pharmaceutical agents, which records all prescriptions dispensed at all of the pharmacies in Sweden. Strict registration routines and internal controls support the accuracy of the database.

Data were stratified by age and sex, and odds ratios were calculated using multilevel logistic regression. ${ }^{2}$ Potential drug interactions were classified according to clinical relevance (types A, B, C, and D) and documented evidence (types 1, 2, 3, and 4)-for example, subtype D4 indicates an interaction with greater potential clinical relevance than that classified as subtype A1 (figure). ${ }^{34}$

Of the 962013 prescriptions dispensed by pharmacies, $130765(13.6 \%)$ included at least one potential drug interaction. The number of potential drug interactions increased with the patient's age and with the number of drugs per prescription (data not shown). Clinically relevant potential drug interactions that could be controlled by adjusting the dose (type $\mathrm{C}$ ) were found in 29 991/371402 (8.1\%) men and $44754 / 545857$ (7.6\%) women. Potential interactions that might have serious clinical consequences (type D) were found in 13282 (1.4\%) of the prescriptions (11.4\% (5269/371 402) men and 1.4\% (8013/590 611) women). However, $6936(52.2 \%)$ of these potential interactions were between ipratropium and $\beta$ adrenergic agonists, which result in an increased risk of acute angle closure glaucoma only when the drugs are used in nebulised form-an uncommon treatment.

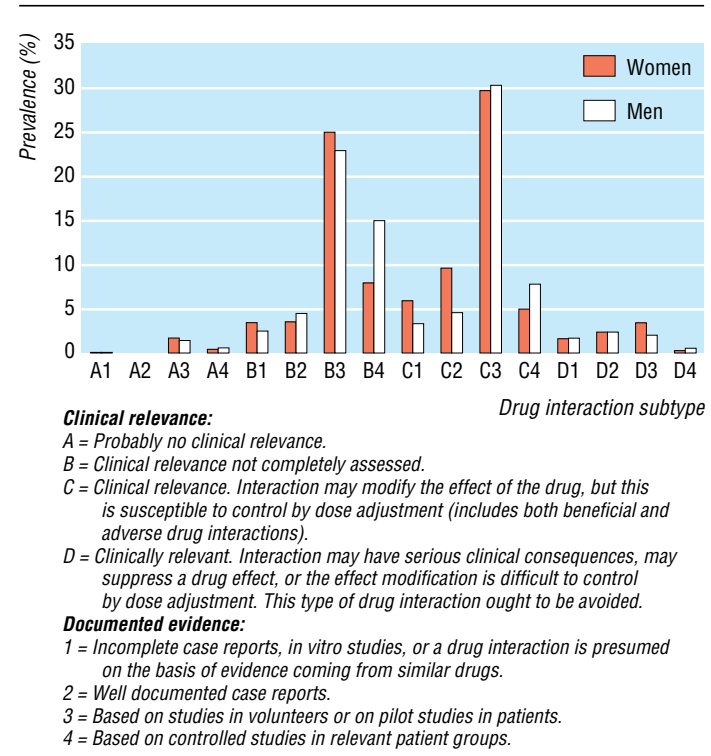

Prevalence of potential drug-drug interaction subtypes ${ }^{34}$ among 962013 prescriptions containing two or more drugs dispensed to patients aged 15-95 from Swedish pharmacies in January 1999.

After adjusting for the number of drugs dispensed, we found that combinations of drugs with potential interactions that may have serious clinical consequences (type D) were less likely to be prescribed to women than men (relative risk $0.88 ; 95 \%$ confidence interval 0.85 to 0.92 ).

Of the potential type D interactions, 2358 were between potassium supplements and potassium sparing diuretics-a combination that may result in severe and even life threatening hyperkalaemia. The combination of warfarin dispensed with a nonsteroidal anti-inflammatory drug (subtype D4), which can increase the risk of gastrointestinal bleeding due to gastric mucosal damage by the non-steroidal antiinflammatory drug and the anticoagulant effect of warfarin, was found on 644 occasions.
Department of
Community
Medicine, Lund
University, Malmö
University Hospital,
S-205 02 Malmö,
Sweden 
Dextropropoxyphene was dispensed with alprazolam on 261 occasions (this combination may increase the central depressant effects of alprazolam) and with carbamazepine on 240 (this combination may cause serious toxic effects by increasing plasma concentrations of carbamazepine). Cisapride was dispensed with erythromycin on five occasions, with clarithromycin on three, fluconazole on 24, and itraconazole on one; any of these combinations may result in torsades de pointes, syncope, cardiac arrest, and sudden death.

\section{Comment}

Although the percentage of potential drug interactions that may have serious clinical consequences (type D) was low (1.4\%), serious and potentially fatal drug interactions-for example, NSAID and warfarin, potassium supplements and potassium sparing diuretics, dextropropoxyphene and carbamazepine, and cisapride and fluconazole-were detected. The risk of interactions with cisapride was known in $1996,{ }^{5}$ and cisapride, which is still available in Sweden, is being withdrawn in many countries.

Prescribing pairs of drugs with potential interactions increases the risk of, but need not lead to, an adverse reaction. Many drug interactions are susceptible to control by dose adjustment; moreover, some are beneficial and are exploited in therapeutics.

National monitoring of potential drug interactions in Sweden is feasible. Differences in healthcare systems need to be considered when extrapolating the results of this study to other countries.
Presented in part at the International Society of Pharmacoepidemiology annual meeting in Barcelona, Spain, 19-23 August 2000. We are grateful to the Swedish Centre for Epidemiology (National Board of Health and Welfare) and the National Corporation of Swedish Pharmacies (Apoteket AB, formerly Apotekesbolaget) for access to the Swedish Health Care Database on Pharmaceutical Agents, and to Frank Wollheim, Department of Rheumatology, Lund University Hospital for his support.

Contributors: JM had the original idea for the article, designed and performed the analysis and interpretation of the data, and drafted, wrote, and revised the content. JF programmed the database. All authors were involved in the study design, data interpretation, content revision, and approval of the final version.JM is the guarantor of the paper.

Funding: Nätverk för Läkemedelsepidemiologi (NEPI) foundation; Government grant (JM) from Avtal om Läkarutbildning och Forskning (founding document number M : E 39 $390 / 98)$

Competing interests: None declared.

1 Stockley IH. Drug interactions: a source book of adverse interactions, their mechanisms, clinical importance and management. London: Pharmaceutical Press, 1996.

2 Rasbash J, Browne W, Goldstein H, Yang M, Plewis I, Healy M, et al. A user's guide to MLwiN. London: Institute of Education, University of London, 1999.

3 Sjöqvist F. Drug interactions. In: The Swedish Drug Compendium "FASS" Läkemedel $i$ Sverige. Förtecking över humanläkemedel. Stockholm: LINFO Läkemedelsinformation AB, 1999:1383-1453.

4 Sjöqvist F. Drug interactions. In: The Swedish Drug Compendium "FASS". Läkemedel $i$ Sverige. Förtecking över humanläkemedel. Stockholm: LINFO Läkemedelsinformation AB, 2000:1481-1556.

5 Biverkningsinformation: Prepulsid (cisaprid) - hjärtarytmi: Påminnelse. Information från Läkemedelsverket 1996;7(6):27.

(Accepted 29 March 2001)

\title{
Rationing in the NHS: audit of outcome and acceptance of restriction criteria for minor operations
}

\author{
Ciaran P O’Boyle, Richard P Cole
}

Odstock Centre for Burns, Plastic and Maxillofacial Surgery, Salisbury District Hospital, Salisbury SP2 8B] Ciaran P O'Boyle research fellow Richard P Cole consultant plastic surgeon

Correspondence to:

C P O'Boyle ciaranoboyle@ saintly.com

BMJ 2001;323:428-9
General practitioners' referrals for skin lesion excisions constitute a large proportion of cases seen at plastic surgery clinics. Escalating rates of skin cancer have increased the numbers of urgent referrals due to suspicious looking skin lesions. As a result, patients with clinically benign lesions spend long periods on waiting lists, exceeding the waiting times agreed in negotiated contracts.

In March 1999, a total of 666 patients had been waiting over one year for minor plastic surgery at Salisbury District Hospital. In response, Salisbury Health Care NHS Trust and Wiltshire Health Authority proposed a new system of contract exclusions, whereby only patients with lesions that suggested malignancy or that were disfiguring or potentially disfiguring would be seen. The health authority and the trust assumed that excluded patients would not be seen or treated elsewhere. The consultant plastic surgeons reviewed the referral letters for patients who were not given an operation and returned the letters with explanatory notes.

This study aimed to assess the acceptability of the new system among patients and general practitioners and to determine the outcome of cases excluded under the new criteria.

\section{Methods and results}

Details of all referrals rejected under the new system were collected for six months after its inception on 1 September 1999. In each case, the site and description of the lesion were recorded. General practitioners and patients were contacted by telephone to assess their satisfaction with the system and to determine whether further referrals for excision had been made. The histological diagnosis was obtained for lesions excised after re-referral.

In six months, 112 referrals were rejected. Of these, 99 contactable patients (134 lesions) were followed up; 103 lesions (77\%) were in the head and neck. In many referral letters the clinical description was non-specific but did not suggest malignancy or disfigurement.

Nineteen $(19 \%)$ patients later had their lesions excised; 18 patients had benign pathology, and one had a squamous cell carcinoma. The patient with the carcinoma had been refused treatment solely on the basis of a referral letter-on grounds that this was a cosmetic problem-and afterwards sought a private consultation and subsequent excision. 